\title{
Article \\ Factors Associated with Physical Activity among People with Hypertension in a Rural Area in Bangladesh: Baseline Data from a Cluster Randomized Control Trial
}

\author{
Fakir M Amirul Islam 1,2 \\ 1 School of Health Sciences, Swinburne University of Technology, Hawthorn, VIC 3122, Australia; \\ fislam@swin.edu.au \\ 2 Organization for Rural Community Development (ORCD), Dariapur, Narail 7500, Bangladesh
}

Citation: Islam, F.MA. Factors Associated with Physical Activity among People with Hypertension in a Rural Area in Bangladesh: Baseline Data from a Cluster Randomized Control Trial. Int. J. Environ. Res. Public Health 2021, 18, 7365. https://doi.org/10.3390/ijerph 18147365

Academic Editor: Gareth Stratton

Received: 5 May 2021

Accepted: 7 July 2021

Published: 9 July 2021

Publisher's Note: MDPI stays neutral with regard to jurisdictional claims in published maps and institutional affiliations.

Copyright: (C) 2021 by the author. Licensee MDPI, Basel, Switzerland. This article is an open access article distributed under the terms and conditions of the Creative Commons Attribution (CC BY) license (https:// creativecommons.org/licenses/by/ $4.0 /)$.
Abstract: The health benefits of physical activity (PA) are well recognized, and PA levels vary in different populations. The study aimed to investigate PA levels and associated sociodemographic factors among people with hypertension in a rural area in Bangladesh. Baseline data were part of a cluster randomized controlled trial of 307 adults aged 30-75 years to study the effectiveness of PA and lifestyle changes in lowering blood pressure. The outcome variables were PA at work, commuter, recreation, metabolic equivalent task (MET)-minute per week and sitting time. Total 68 (22.1\%) people participated in vigorous-intensity activity, $23(7.5 \%)$ participated in moderate-intensity sports. Overall, $83 \%$ of people were physically active more than 600 MET-min. Women (OR 2.95, 95\% CI, 1.36-6.39) compared to men, and people with no education (OR 4.47, 95\% CI, 1.62-12.33) compared to people with secondary school certificates or above were less physically active. Of total PA, 63\% were work-related, and $1 \%$ were recreation-related for women, and these figures were $55 \%$ and $3 \%$ for men. The study reports that vigorous-intensity PA is low, and recreation time is minimal. Routine PA, especially for women and people with low education levels, should be encouraged to increase PA to manage hypertension.

Keywords: rural area; Bangladesh; high blood pressure; association; logistic regression

\section{Introduction}

Worldwide, more than 5 million people die due to complications from being physically inactive $[1,2]$. The prevalence of physical inactivity is increasing irrespective of the socioeconomic condition of the countries [3], and thus, it was considered an urgent public health priority $[2,4]$. A 75-min vigorous-intensity PA or $150 \mathrm{~min}$ per week of moderate-intensity PA or combination is suggested to reduce the risk of chronic diseases [2,3].

In terms of health benefit, previous studies reported that participating in vigorousintensity PA was associated with a reduced risk of cardiovascular diseases and mortality among adults compared to that of those participating in moderate-intensity PA [5-7]. Therefore, it is essential to know PA levels' status and develop various population-specific public health awareness programs to prevent and control chronic diseases $[8,9]$.

Bangladesh is transitioning towards a middle-income country with a significant increase in life expectancy [10], urban settlements, and economic development [11,12], which is contributing to the sedentary behaviour to rising NCDs [13-15]. Thus, the number of years living with numerous chronic conditions is also expected to increase, which is evident from previous studies $[16,17]$. However, data on the prevalence of total PA and its composition and associated factors in Bangladesh are insufficient. Two earlier studies $[18,19]$ reported that $65 \%$ and $62 \%$ of adults aged 25 years or older were physically active, but the studies did not report the factors associated with PA. A recent survey by Moniruzzaman [20] reported the prevalence of PA and its associated factors. The study revealed that $58.1 \%$ of rural adults aged $25-64$ had moderate to a high level of PA, with a 
significant difference between women (49\%) and men (66\%). Compared to these findings, studies in other low-medium-income countries reported that a high proportion of people met the world health organization recommendation for PA. For example, in Nepal, 97\% of people met the world health organization recommendation for PA [21], as did Uganda (94.3\%) [22], and Mozambique (90\%) [23]. Previous studies conducted in low- and middleincome countries, including Bangladesh, reported that women, older age, higher education, and higher socioeconomic status were associated with a higher prevalence of physical inactivity $[18,20,22-25]$.

Most of the previous studies conducted in Bangladesh were among the general population $[18,20,26]$. The patterns of PA could vary among people with a known chronic condition. Generally, people display more awareness of the risk factors of the situation and are more likely to act upon them to manage the diseases. For example, studies report that people who had diabetes or ocular diseases were more likely to be aware of the associated risk factors $[27,28]$. Similarly, those aware of diabetes complications were more likely to attend a diabetic retinopathy screening program [29], indicating participating in PA in people with any chronic conditions could be higher. The current study was among the people with hypertension. Previous studies reported that less than one-fifth of people with hypertension in low- to middle-income countries (LMICs) could control their blood pressure at the targeted level $[30,31]$. Data from the current study suggest that only one-third of the participants could maintain their blood pressure level with the cut-off of SBP $\leq 140 \mathrm{mmHg}$ or DBP $\leq 90 \mathrm{mmHg}$ [32], although generally, the prevalence of PA among rural people in LMICs was high [18-24]. Previous studies reported that participating in vigorous-intensity PA was associated with a reduced risk of cardiovascular diseases and mortality than those taking moderate-intensity PA [5-7]. The proportion of vigorous-intensity, moderate-intensity, or sedentary lifestyles among people with known hypertension is unknown. Findings from this study can help in conducting targeted intervention to manage blood pressure at the targeted level in LMICs. We aimed to measure the PA levels and associated sociodemographic factors among participants with known hypertension in a rural area in Bangladesh.

\section{Materials and Methods}

\subsection{Study Sample and Location}

The current study was a part of a cluster RCT that was conducted since December 2020 to study the effectiveness of PA and lifestyle changes in lowering blood pressure. The cluster RCT has consisted of 307 participants aged 30-75 years, with an equal proportion of men and women from the Banshgram Union in the Narail District. Narail is situated approximately $200 \mathrm{~km}$ away from the capital city Dhaka of Bangladesh. The administrative unit of Bangladesh can be briefly reported with over 163 million people divided into 64 districts. Each district divides into Upazilas (subdistricts), and each Upazila further divides into Unions which consist of 15-20 villages. Banshgram is such a Union with 18 villages [33]. The cluster RCT was reported elsewhere [34].

\subsection{Participants}

The background of the current cluster RCT is that a cross-sectional study was conducted in the Banshgram Union among 3104 participants of age 30-89 years in 2013 to report several outcomes, including the prevalence of diabetes and prediabetes [35] and known and undiagnosed hypertension. The study identified $1242(40 \%)$ participants with hypertension [36] with a cut-off of $140 / 90 \mathrm{mmHg}$ [37] who were the source population for the current cluster RCT. However, the current study was limit to the upper age to 75 years, leaving 1072 eligible participants for the cluster RCT from where 307 participants were recruited. Ten to twenty participants were recruited from each village based on the village size. The study location and the demographic characteristics of the source's population were described previously [36]. 


\subsection{Statistical Power}

The original study is a cluster RCT with a sample size of 307 participants. This sample size was used to estimate if it had sufficient statistical power to estimate the proportion of physically active people, similar to that reported in a previous study in Bangladesh. A prior study in Bangladesh [20] reported that $60 \%$ of people aged 25-64 were physically active. If the proportion of physically active people in the current sample would be between $40-80 \%$, the sample size was adequate with a statistical power greater than or equal to $95 \%$ and a significance level of 0.05 .

\subsection{Data Collection}

Data were collected on PA, blood pressure and other variables from all participants at baseline. For the original study of a cluster randomized controlled trial, 156 participants were recruited from cluster 1 , consisting of nine villages. The rest of the 307 participants were recruited from cluster 2, consisting of the rest of the villages [34]. A local nongovernment organization (NGO) in the study area in Bangladesh made the study accessible. The local investigators of the NGO conducted the recruitment along with trained data collectors. The investigators and the data collectors set up communication with the potential participants over the telephone or through direct contact and collected data from face-to-face interviews. Before data collection, the local investigators and the data collectors received training through four zoom meetings and consultation over the telephone by the chief investigator if more clarification was needed for data collection.

\subsection{Ethics Approval and Consent Processes}

Swinburne University of Technology Human Research Ethics Committee (Review reference: 20202723-5020) approved the study. The study adhered to the tenets of the Declaration of Helsinki. Written information about the project was given to each participant and was discussed their volunteer involvement in this project. The information was verbally explained to those who could not read. Upon receiving their written consents, the local investigator enrolled them in the study by assuring that participants had full rights to withdraw from the study at any stage if they wished. Participants' decision to take part would not influence their relationship with the local NGO.

\subsection{Participants Benefits}

Participation in this study is voluntary. During the intervention, a total of 20 Omron blood pressure measuring units, one unit for each group of 15 participants, was provided to allow the monitoring of blood pressures. The machines were provided to the 20 team leaders for use by the participants and other community members. After the intervention, the blood pressure devices were not taken back, allowing the future monitoring of blood pressure in the community.

\subsection{Measuring Physical Activity}

We used the Global Physical Activity Questionnaire version 2 (GPAQ-2) [38], developed by the $\mathrm{WHO}$ for PA surveillance in developing countries, to measure PA levels. This questionnaire consisted of 16 questions with three domains-PA at work, PA for transportation (travel to and from places), and leisure PA, such as participating in any sports programs. Sedentary behaviour was measured by hours of sitting per day. Physical activity was categorized into vigorous- and moderate-intensity activities. Definitions of vigorous- and moderate-intensity activities and the questionnaire were described in detail in the GPAQ-2 guidelines [38]. The total PA comprised of work, commuting, and recreation activities were converted to metabolic equivalent tasks (MET) in minutes per week, which is the unit to express the intensity of PA. The methods for MET calculation were described elsewhere [18,25]. 


\subsection{Outcome Measures}

The outcome measures were as follows: work-related PA, including self-reported vigorous-intensity and moderate-intensity activities and their associated weekly hours spent. Commuter or travel time to and from places reported as moderate-intensity activity and weekly time spent, and recreation activity reported as vigorous-intensity sports or moderate-intensity sports and their weekly time spent, and sedentary behaviour measured as sitting time more than four hours per day. These were binary outcomes reported as "yes" for taking part in any PA and "no" for not taking part in the PA. Finally, overall PA measured as MET-min (MET-min) per week, which was classified as insufficient PA recommended by WHO with a cut-off of 0 to 600 MET-min, moderate to high PA with a cut-off of 601-6000 MET-min per week, and increased PA with a cut-off of greater than 6000 MET-min per week. Overall, PA was again reclassified below the recommended level and at least recommended level of PA.

\subsection{Sociodemographic Factors}

Sociodemographic variables included age, sex, the highest level of education, and socioeconomic status. The level of education was categorized as no schooling, primary to high school (grades 1 to 9), secondary school certificate, or above. Socioeconomic was assessed by a previously used method developed and tested in Hong Kong in terms of income insecurity and an informal labour market [39]. SES status was categorized based on the financial stability in the previous year of data collection. SES was defined as poor if participants had economic instability in the last year of data collection, middle class if they had financial instability some of the time, and wealthy if they did not have any financial instability. The participants' occupation was categorized as a homemaker, selfmanaged business, farmers, and employees who include government and nongovernment employees. Self-reported diabetes status was classified as "no diabetes", "with diabetes", and "unknown diabetes".

\subsection{Statistical Analysis}

Data were cleaned according to the GPAQ-2 data cleaning guidelines. In the data cleaning stage, any implausible values such as participating in any activities more than seven days a week or inconsistent answers such as days in participation were zero were checked. None of the participants gave implausible or inconsistent responses. The binary logistic regression technique was used to report the association of the sociodemographic variables with the outcome variables PA domain related to work, commuter, sitting time, and the overall PA measured by MET-min per week. The results were presented as an odds ratio with a 95\% confidence interval (CI). Median and inter-quartile range (IQR) of time spent per week for work and commuter related PA were compared using the Krusical-Wallis test. Statistical software SPSS (IBM SPSS Statistics for Windows, Version 27.0.; IBM Corp.: Armonk, NY, USA) was used for the analysis.

\section{Results}

Of the total participants, the men to women ratio was equal. Half of the participants had primary to high school level of education, half of the participants were homemakers, one-third of the participants were poor, and the rest were middle class or wealthy. Fifteen per cent of the participants were $30-40$ years of age, $50 \%$ were $40-59$ years, and the rest were 60 to 75 years of age.

Table 1 shows the prevalence of vigorous-intensity and moderate-intensity PA at work. Of total participants, $22.1 \%$ of people participated in a vigorous-intensity activity with median (quartile $1(\mathrm{Q} 1)$, quartile $3(\mathrm{Q} 3)) 15(6,25)$ hours, and $62.2 \%$ participated in a moderate-intensity activity with median (Q1, Q3) $12(7,21)$ per week. After adjustment for age, sex, level of education, and occupation, men odds ratio (OR) ( $95 \%$ confidence interval (CI)) $3.44(1.8,6.6)$ compared to women, younger people such as people aged below 40 years (OR $(95 \%$ CI $) 7.63(2.71,21.5))$ compared to people aged 60 years or older, and being poor 
was associated with a higher proportion of participating in a vigorous-intensity activity. Homemakers, employees and businesspersons were associated with a lower proportion of participating in a vigorous-intensity activity than farmers. Sex, level of education and socioeconomic condition were not associated with moderate-intensity activity at work.

Table 1. Activity at work and its associated sociodemographic factors in people with high blood pressures in a rural area in Bangladesh.

\begin{tabular}{|c|c|c|c|c|c|c|c|}
\hline \multirow[b]{3}{*}{ Factors } & \multirow[b]{3}{*}{$\begin{array}{c}\text { No of } \\
\text { Participants }\end{array}$} & \multicolumn{6}{|c|}{ Activity at Work (Yes/No of Participants) \%, Weekly Hours Spent, Median (IQR) } \\
\hline & & \multicolumn{3}{|c|}{ Vigorous-Intensity Activity } & \multicolumn{3}{|c|}{ * Moderate-Intensity } \\
\hline & & $n(\%)$ & OR $(95 \% \mathrm{CI}) \ddagger$ & $\begin{array}{l}\text { Median } \\
(\mathrm{IQR})^{\dagger}\end{array}$ & $n(\%)$ & OR $(95 \% \mathrm{CI}) \ddagger$ & $\begin{array}{l}\text { Median } \\
(\mathrm{IQR})^{\dagger}\end{array}$ \\
\hline Total & 307 & $68(22.1)$ & & $15(6,25)$ & $191(62.2)$ & & $12(7,21)$ \\
\hline \multicolumn{8}{|l|}{ Sex } \\
\hline Female & 154 & $26(16.9)$ & 1.00 (reference) & $11(6,16)$ & $96(62.3)$ & 1.00 (reference) & $14(7,21)$ \\
\hline Male & 153 & $42(27.5)$ & $3.44(1.80,6.61)$ & $18(8,30)$ & $95(62.1)$ & $1.05(0.61,1.83)$ & $12(7,21)$ \\
\hline \multicolumn{8}{|l|}{$\begin{array}{c}\text { Age } \\
\text { group, years }\end{array}$} \\
\hline Below 40 & 46 & 15 (32.6) & $7.63(2.71,21.5)$ & $9(6,20)$ & 38 (82.6) & $4.08(1.61,10.4)$ & $15(8,25)$ \\
\hline $40-59$ & 160 & $42(26.3)$ & $4.03(1.84,8.83)$ & $15(8,28)$ & 107 (66.9) & $2.23(1.27,3.9)$ & $12(6,21)$ \\
\hline 60 or older & 101 & $11(10.9)$ & 1.00 (reference) & $11(4,23)$ & $46(45.5)$ & 1.00 (reference) & $12(7,16)$ \\
\hline \multicolumn{8}{|l|}{$\begin{array}{c}\text { Level of } \\
\text { Education }\end{array}$} \\
\hline No education & 99 & $21(21.2)$ & $2.48(0.89,6.88)$ & $18(6,35)$ & $52(52.5)$ & $0.48(0.21,1.12)$ & $10(6,18)$ \\
\hline $\begin{array}{l}\text { Primary to } \\
\text { high school }\end{array}$ & 148 & $36(24.3)$ & $2.05(0.85,4.93)$ & $15(6,23)$ & $96(64.9)$ & $0.61(0.28,1.30)$ & $13(7,21)$ \\
\hline SSC or above & 59 & 11 (18.6) & 1.00 (reference) & $9(4,12)$ & $43(72.9)$ & 1.0 (reference) & $14(8,28)$ \\
\hline \multicolumn{8}{|l|}{$\begin{array}{l}\text { Socioeconomic } \\
\text { status }\end{array}$} \\
\hline Poor & 92 & $27(29.3)$ & $1.88(1.01,3.49)$ & $15(6,30)$ & $58(63.0)$ & $1.25(0.72,2.17)$ & $12(7,20)$ \\
\hline Middle class & 214 & $41(19.2)$ & 1.00 (reference) & $14(6,21)$ & $132(61.7)$ & 1.00 (reference) & $12(7,21)$ \\
\hline \multicolumn{8}{|l|}{ Occupation } \\
\hline Farmer & 66 & $28(42.4)$ & 1.00 (reference) & $20(12,30)^{\mathrm{a}}$ & $46(69.7)$ & 1.00 (reference) & $10(6,18)$ \\
\hline Housewife & 146 & $26(17.8)$ & $0.24(0.07,0.89)$ & $11(6,16)^{\mathrm{a}}$ & $94(64.4)$ & $1.24(0.17,9.01)$ & $14(6,21)$ \\
\hline Employees & 53 & $5(9.4)$ & $0.19(0.06,0.66)$ & $9(9,10)^{a}$ & $24(45.3)$ & $0.31(0.12,0.81)$ & $10(8,15)$ \\
\hline Business & 24 & $5(20.8)$ & $0.27(0.08,0.91)$ & $6(4,35)^{b}$ & $15(62.5)$ & $0.42(0.14,1.27)$ & $14(8,30)$ \\
\hline \multicolumn{8}{|l|}{$\begin{array}{l}\text { Diabetes } \\
\text { Status }\end{array}$} \\
\hline No diabetes & 217 & 45 (20.7) & 1.00 (reference) & $13(6,21)^{a}$ & $129(59.4)$ & 1.00 (reference) & $14(8,21)^{\mathrm{a}}$ \\
\hline Diabetes & 41 & $6(14.6)$ & $0.73(0.27,1.97)$ & $27(14,35)^{b}$ & $21(51.2)$ & $0.63(0.31,1.29)$ & $7(5,12)^{b}$ \\
\hline Unknown & 49 & $17(34.7)$ & $1.63(0.79,3.39)$ & $15(6,21)^{\mathrm{a}}$ & $41(83.7)$ & $2.74(1.19,6.33)$ & $10(7,20)^{\mathrm{a}}$ \\
\hline
\end{tabular}

* 51 participants did either vigorous or moderate-intensity work; ${ }^{\dagger}$ without any subscript or subscript with the same letter, e.g., "a" are for the nonsignificant difference. Different letters " $a$ " and " $\mathrm{b}$ " indicates a significant difference at least at a 5\% level of significance; $¥$ OR $(95 \% \mathrm{CI})$ adjusted for variables in model.

Table 2 shows PA levels related to travel and recreation and sedentary lifestyle measured by sitting time more than $4 \mathrm{~h}$ per day. Physical activity related to travel, $77.2 \%$ of people spent more than $10 \mathrm{~min}$ travelling to and from places with median (Q1, Q3) 7 (7, 14) hours per week. Men OR $(95 \%$ CI) $3.84(1.94,7.61)$ compared to women, people aged 
40 years or younger OR $(95 \% \mathrm{CI}) 3.75(1.16,12.1)$ compared to those aged 60 years or older were associated with a higher proportion of PA related to travel. People with no education or employees were associated with a lower proportion of time spending more than $10 \mathrm{~min}$ travelling to and from places.

Table 2. Travel to and from places, recreational activities, and sedentary lifestyle in people with high blood pressure in a rural area in Bangladesh.

\begin{tabular}{|c|c|c|c|c|c|c|c|c|c|}
\hline \multirow[b]{3}{*}{ Factors } & \multirow[b]{3}{*}{$\begin{array}{c}\text { No. of } \\
\text { Participants }\end{array}$} & \multicolumn{8}{|c|}{ Physical Activity (Yes/No of Participants) \%, Weekly/Daily Hours Spent, Median (IQR) } \\
\hline & & \multicolumn{3}{|c|}{$\begin{array}{l}\text { Travel to and from Places for More Than } \\
10 \text { min Per Day (Weekly Hours) }\end{array}$} & \multicolumn{3}{|c|}{$\begin{array}{c}\text { Moderate-Intensity Sports } \\
\text { (Weekly Hours) }\end{array}$} & \multicolumn{2}{|c|}{$\begin{array}{l}\text { Sitting Time } \geq 4 \mathrm{~h} \text { Per } \\
\text { Day }\end{array}$} \\
\hline & & $n(\%)$ & OR $(95 \% \mathrm{CI}) \ddagger$ & $\begin{array}{l}\text { Median } \\
\text { (IQR) }^{+}\end{array}$ & $n(\%)$ & OR $(95 \% \mathrm{CI}) \ddagger$ & $\begin{array}{l}\text { Median } \\
\left({\text { IQR })^{+}}^{+}\right.\end{array}$ & $n(\%)$ & OR $(95 \% \mathrm{CI}) \ddagger$ \\
\hline Total & 307 & $237(77)$ & & $7(4,14)$ & $23(7.5)$ & & $5(2,10)$ & 143(47) & \\
\hline \multicolumn{10}{|l|}{ Sex } \\
\hline Female & 154 & $103(67)$ & 1.00 (reference) & $6(3,12)$ & $5(3.2)$ & 1.00 (reference) & $4(1,8)$ & $70(46)$ & $0.83(0.49,1.41)$ \\
\hline Male & 153 & $134(88)$ & $3.84(1.94,7.61)$ & $7(4,14)$ & $18(12)$ & $4.95(1.55,15.8)$ & $4(2,10)$ & $73(48)$ & 1.00 (reference) \\
\hline \multicolumn{10}{|l|}{$\begin{array}{c}\text { Age } \\
\text { group, years }\end{array}$} \\
\hline Below 40 & 46 & $41(89)$ & $3.75(1.16,12.1)$ & $7(4,14)$ & $10(22)$ & $6.74(1.7,26.8)$ & $4(2,7)$ & $12(26)$ & 1.00 (reference) \\
\hline $40-59$ & 160 & $123(77)$ & $1.86(0.95,3.64)$ & $7(4,14)$ & $8(5.0)$ & $1.44(0.43,4.8)$ & $6(1,9)$ & $66(41)$ & $1.83(0.84,3.97)$ \\
\hline $60+$ & 101 & $73(72)$ & 1.00 (reference) & $7(4,14)$ & $5(5.0)$ & 1.00 (reference) & $7(2,14)$ & $65(64)$ & $4.71(2.0,11.08)$ \\
\hline \multicolumn{10}{|l|}{$\begin{array}{l}\text { Level of } \\
\text { education }\end{array}$} \\
\hline $\begin{array}{c}\text { No } \\
\text { education }\end{array}$ & 99 & $67(68)$ & $0.25(0.07,0.93)$ & $7(4,14)^{a}$ & $5(5.1)$ & $0.67(0.15,3.05)$ & $8(4,10)$ & $52(53)$ & $1.12(0.50,2.50)$ \\
\hline $\begin{array}{l}\text { Primary to } \\
\text { high school }\end{array}$ & 148 & $114(77)$ & $0.31(0.09,1.11)$ & $8(5,14)^{b}$ & $9(6.1)$ & $0.67(0.19,2.32)$ & $6(1,12)$ & $63(43)$ & $0.91(0.71,1.15)$ \\
\hline $\begin{array}{l}\text { SSC or } \\
\text { above }\end{array}$ & 59 & $56(95)$ & 1.00 (reference) & $6(4,10)^{a}$ & $9(15)$ & 1.0 (reference) & $4(2,4)$ & $27(46)$ & 1.00 (reference) \\
\hline \multicolumn{10}{|c|}{$\begin{array}{l}\text { Socioeconomic } \\
\text { status }\end{array}$} \\
\hline Poor & 92 & $71(77)$ & $1.3(0.69,2.44)$ & $7(4,12)$ & $9(9.8)$ & $2.78(1.0,7.85)$ & $9(3,12)$ & $38(41)$ & 1.00 (reference) \\
\hline $\begin{array}{l}\text { Middle } \\
\text { class }\end{array}$ & 214 & $165(77)$ & 1.00 (reference) & $7(4,14)$ & $13(6.1)$ & 1.00 (reference) & $4(1,6)$ & $105(49)$ & $1.52(0.89,2.6)$ \\
\hline \multicolumn{10}{|l|}{ Occupation } \\
\hline Farmer & 66 & $61(92)$ & 1.00 (reference) & $8(6,14)$ & $4(6.1)$ & 1.00 (reference) & $5(1,10)$ & $32(49)$ & 1.00 (reference) \\
\hline Housewife & 146 & $101(69)$ & $1.06(0.13,8.86)$ & $7(3,12)$ & $5(3.4)$ & $1.21(0.20,6.32)$ & $4(1,8)$ & $65(45)$ & $0.79(0.13,4.73)$ \\
\hline Employees & 53 & $38(72)$ & $0.23(0.06,0.82)$ & $7(4,14)$ & $3(5.7)$ & $1.31(0.21,7.95)$ & $2(1,4)$ & $32(60)$ & $1.18(0.49,2.86)$ \\
\hline Business & 24 & $23(96)$ & $1.13(0.12,10.4)$ & $7(4,14)$ & $5(21)$ & $2.98(0.55,16.1)$ & $9(6,14)$ & $5(21)$ & $0.29(0.09,0.95)$ \\
\hline \multicolumn{10}{|l|}{$\begin{array}{l}\text { Diabetes } \\
\text { status }\end{array}$} \\
\hline $\begin{array}{c}\text { No } \\
\text { diabetes }\end{array}$ & 217 & $162(75)$ & 1.00 (reference) & $7(4,14)$ & $17(7.8)$ & 1.00 (reference) & $5(2,8)$ & $99(46)$ & 1.00 (reference) \\
\hline Diabetes & 41 & $34(83)$ & $1.45(0.57,3.68)$ & $7(4,14)$ & $1(2.4)$ & $0.28(0.03,2.33)$ & 10 & $27(66)$ & $2.43(1.16,5.10)$ \\
\hline Unknown & 49 & $41(84)$ & $1.15(0.48,2.78)$ & $8(5,14)$ & $5(10)$ & $0.93(0.27,3.19)$ & $1(1,4)$ & $17(35)$ & $0.85(0.43,1.68)$ \\
\hline
\end{tabular}

${ }^{\dagger}$ without any subscript or subscript with same letter, e.g., "a" are for the nonsignificant difference. Different letters "a" and " $b$ " indicates a significant difference at least at a $5 \%$ level of significance; $\ddagger$ OR (95\% CI) adjusted for variables in model.

In terms of PA related to recreation, $7.5 \%$ of people participated in a moderate-intensity recreational activity with a median (Q1, Q3) $5(2,10)$ hours per week, only $3(1 \%)$ people participated in a vigorous-intensity sports program. In terms of sedentary behaviour, people aged 60 years or older OR $(95 \%$ CI) $4.71(2.0,11.1)$ compared to people aged $30-40$ years, and people with diabetes OR $(95 \%$ CI $) 2.43(1.16,5.10)$ compared to people 
without diabetes were associated with a higher proportion of sitting time more than $4 \mathrm{~h}$ per day.

Overall, PA measured by metabolic equivalent task (MET)-min per week is shown in Figure 1 and Table 3. Overall, the median (Q1, Q3) MET-min was $4560(1680,8880)$. Figure 1 shows the population pyramid for total PA by sex. Men had zero to a maximum of 30,000 and median (Q1, Q3) $5520(2400,10,560)$ MET-min per week. This result was significantly higher than that in women. Women had zero to a maximum of 20,000 and median (Q1, Q3) $3720(840,6720)$ MET-min per week. Overall, $83 \%$ of people were physically active, as recommended by WHO. Of them, more than 6000 MET-min per week $40.7 \%$ and 600 to 6000 MET-min per week $42.3 \%$. Women OR $(95 \%$ CI) $2.95(1.36,6.39)$ compared to men, people aged 70 years or older OR $(95 \%$ CI $) 3.08(1.49,6.39)$ compared to people aged $40-59$ years, no education OR $(95 \% \mathrm{CI}) 4.47(1.62,12.33)$ compared to people with SSC or above education levels, and employees OR $(95 \%$ CI $) 3.67(1.37,9.79)$ compared to farmers were physically inactive. None of those who were below the age of 40 years or businesspersons were physically inactive.

\section{Population pyramid for total phyiscal activity by sex}

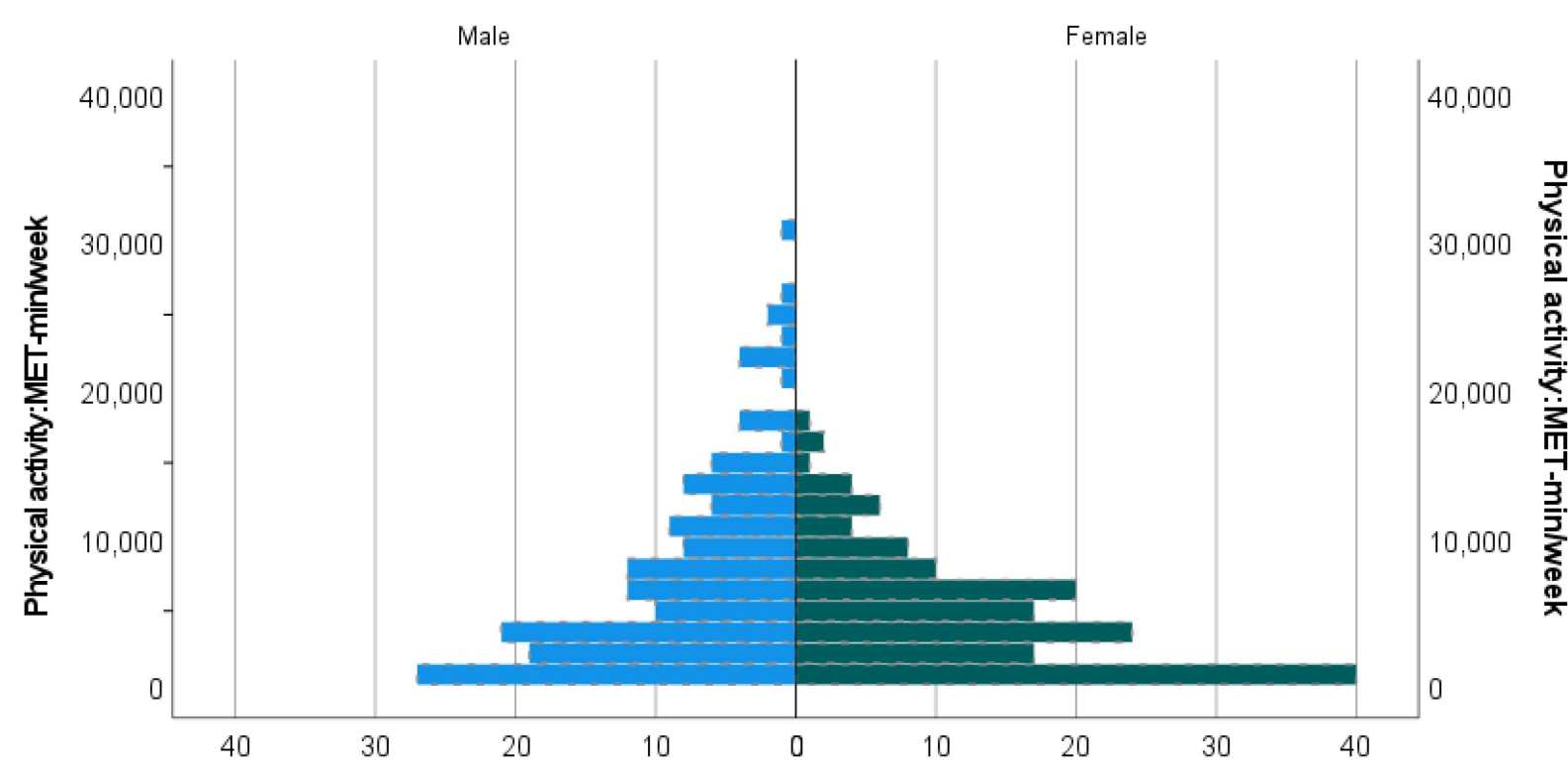

Figure 1. Total physical activity: MET-min per week by sex. 
Table 3. Metabolic equivalent task and its associated sociodemographic factors in people with high blood pressure in a rural area in Bangladesh.

Physical Activity (Yes/No of Participants) \%, Metabolic Equivalent Task (MET)-Minute Per Week

\begin{tabular}{|c|c|c|c|c|c|c|}
\hline \multirow[b]{2}{*}{ Factors } & \multirow[t]{2}{*}{$\begin{array}{c}\text { No. of } \\
\text { Participants }\end{array}$} & \multirow{2}{*}{$\begin{array}{c}\text { MET-min } \\
\text { Median (IQR) }{ }^{\dagger}\end{array}$} & \multirow{2}{*}{$\begin{array}{c}\text { High, }>6000 \\
\text { MET-min }\end{array}$} & \multirow{2}{*}{$\begin{array}{c}\text { Moderate } \\
600-6000 \\
\text { MET-min }\end{array}$} & \multicolumn{2}{|c|}{$\begin{array}{l}\text { Above vs. below Recommended } \\
\text { Level of MET, MET-min } \geq 600 \mathrm{vs} \\
\text { MET-min }<600\end{array}$} \\
\hline & & & & & $n(\%)$ & OR $(95 \%$ CI $) \ddagger$ \\
\hline Total & 307 & $4560(1680,8880)$ & $125(40.7)$ & $130(42.3)$ & $52(16.9)$ & \\
\hline \multicolumn{7}{|l|}{ Sex } \\
\hline Female & 154 & $3720(840,6720)^{\mathrm{a}}$ & $52(33.8)$ & $69(44.8)$ & $33(21.4)$ & $2.95(1.36,6.39)$ \\
\hline Male & 153 & $5520(2400,10,560)^{b}$ & $73(47.7)$ & $61(39.9)$ & $19(12.4)$ & 1.00 (reference) \\
\hline \multicolumn{7}{|l|}{ Age group, years } \\
\hline Below 40 & 46 & $6960(3360,10,320)^{\mathrm{a}}$ & $26(56.5)$ & $20(43.5)$ & - & - \\
\hline $40-59$ & 160 & $5520(2520,9460)^{\mathrm{a}}$ & $75(46.9)$ & $63(39.4)$ & $22(13.8)$ & 1.00 (reference) \\
\hline 60 or older & 101 & $2400(240,5520)^{b}$ & $24(23.8)$ & $47(46.5)$ & $30(29.7)$ & $3.08(1.49,6.39)$ \\
\hline \multicolumn{7}{|l|}{ Level of Education } \\
\hline No education & 99 & $3360(240,6960)^{a}$ & $31(31.3)$ & $39(39.4)$ & $29(29.3)$ & $4.47(1.62,12.33)$ \\
\hline $\begin{array}{c}\text { Primary to high } \\
\text { school }\end{array}$ & 148 & $5040(2400,9360)^{b}$ & $67(45.3)$ & $64(43.2)$ & $17(11.5)$ & $1.40(0.49,3.99)$ \\
\hline SSC or above & 59 & $5040(2400,8880)^{b}$ & $27(45.8)$ & $27(45.8)$ & $5(8.5)$ & 1.00 (reference) \\
\hline \multicolumn{7}{|c|}{ Socioeconomic status } \\
\hline Poor & 92 & $4920(2400,9600)^{\mathrm{a}}$ & $41(44.6)$ & $36(39.1)$ & $15(16.3)$ & 1.00 (reference) \\
\hline Middle class & 214 & $4200(1680,8400)^{b}$ & $83(38.8)$ & $94(43.9)$ & 37 (17.3) & $1.37(0.65,2.86)$ \\
\hline \multicolumn{7}{|l|}{ Occupation } \\
\hline Farmer & 66 & $7320(3360,13,320)^{\mathrm{a}}$ & $44(61.1)$ & $21(29.2)$ & $7(9.7)$ & 1.00 (reference) \\
\hline Housewife & 146 & $4200(1440,6960)^{b}$ & $52(35.6)$ & $66(45.2)$ & $28(19.2)$ & $2.20(0.91,5.32)$ \\
\hline Employees & 53 & $2880(480,5280)^{b}$ & $12(22.6)$ & $26(49.1)$ & $15(28.3)$ & $3.67(1.37,9.79)$ \\
\hline Business & 24 & $6480(1680,13,200)^{\mathrm{a}}$ & $12(50)$ & $12(50)$ & 0 & - \\
\hline \multicolumn{7}{|l|}{ Diabetes Status } \\
\hline No diabetes & 217 & $4560(1200,8640)^{a}$ & $85(39.2)$ & $86(39.6)$ & $46(21.2)$ & 1.00 (reference) \\
\hline Diabetes & 41 & $3720(840,6720)^{b}$ & $12(29.3)$ & $24(58.5)$ & $5(12.2)$ & $0.52(0.18,1.52)$ \\
\hline Unknown & 49 & $5520(2400,10,560)^{\mathrm{a}}$ & $28(57.1)$ & $20(40.8)$ & $1(2)$ & - \\
\hline
\end{tabular}

${ }^{\dagger}$ without any subscript or subscript with same letter, e.g., "a" are for the nonsignificant difference. Different letters "a" and " $b$ " indicates a significant difference at least at a $5 \%$ level of significance; $₹$ OR (95\% CI) adjusted for variables in model.

The composition of total PA by sex is shown in Figure 2. Of the total who met WHO recommended guidelines, $63 \%, 36 \%$, and $1 \%$ were contributed by work-related activity, commuter, and recreational activities, respectively for women, and that contributions were $55 \%, 42 \%$, and $3 \%$ for men with no significant difference between sex in any of the domains contributions to the total PA. 


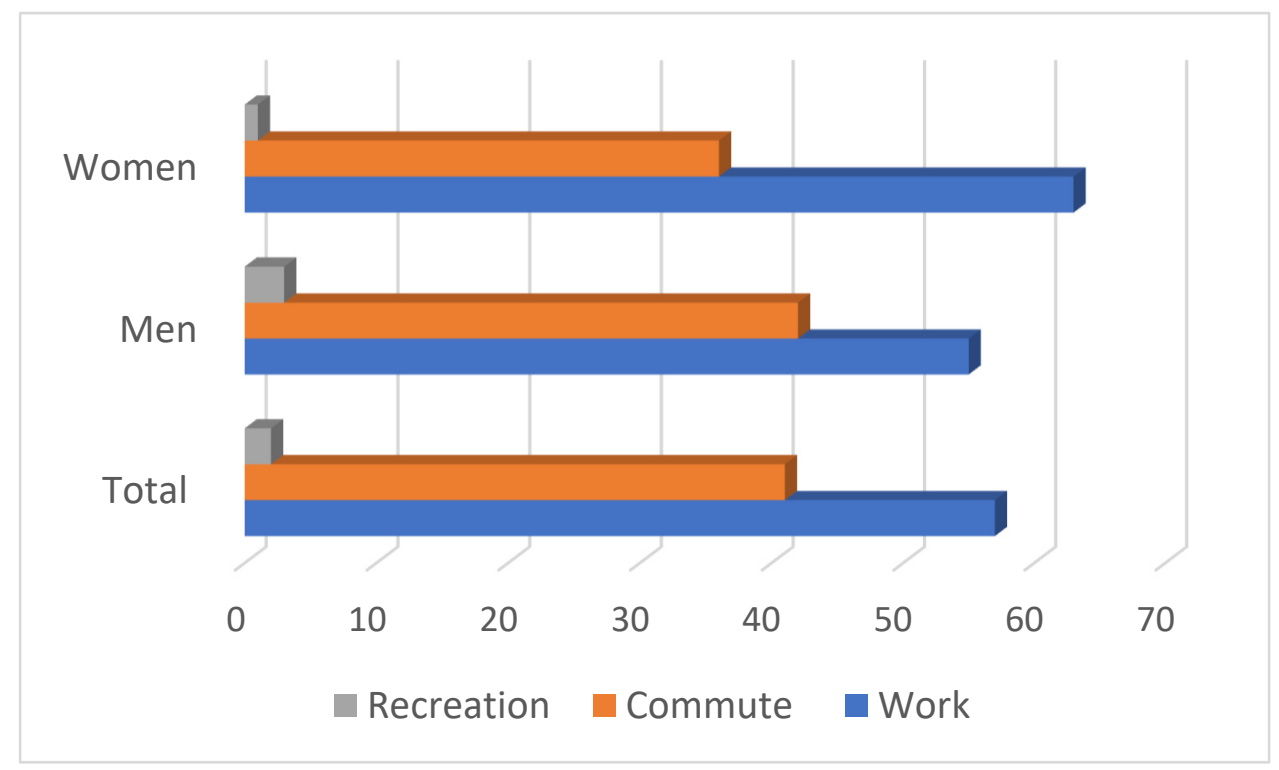

Figure 2. Composition of total physical activity in study sample.

\section{Discussion}

In this study, among participants with hypertension, we estimated the proportion of physically active people, time of active hours per week, sedentary behaviour, and the sociodemographic factors associated with the PA. The study also reported the composition of total PA. The significant findings from the current research include: (1) that more than one fifth of people participated in vigorous-intensity PA, more than three-quarter of people spent more than $10 \mathrm{~min}$ per day to travel to and from places that accounted for moderateintensity activity; (2) based on all three domains of PA, more than $80 \%$ of rural people with hypertension were found to be physically active; (3) the significant factors associated with higher proportion of PA were male gender, and younger people, people with higher education, and people who were involved in laborious activities; (4) among the participants who were found to be active below the WHO recommended level, the proportion of women, older people, and the employees were found to be higher in this group, (5) and that of total PA, one-third was related to commute, a very minimum percentage was from any recreational activities, and the remaining proportion was work-related PA.

The current study found that more than $80 \%$ of people with hypertension were physically active, $57 \%$ of this was work-related, $41 \%$ commuter, and $2 \%$ from sports. Moniruzzaman [20] conducted a study among the general population and reported that $61 \%$ of rural adults aged 25-64 years were moderate to a high level of physically active, $77 \%$ of this was related to work, $21 \%$ related to commuter, and $2 \%$ on sports. The significant difference, especially in the source of PA, could be due to the age difference between the two studies. The current study was conducted on people aged 30 to 75 years, where one-third of the participants were more than 60 years of age compared to $9 \%$ who were 55-64 years in the previous study. The higher proportion of work-related PA in younger people could be attributed to their involvement in regular work than those of the current study. In the case of recreational activities, both studies reported the same proportion. Another study [18] conducted in a national representative survey in Bangladesh on a large sample in 2010 reported that $68.4 \%$ of people had moderate-to-high PA levels; $61 \%$ of this was related to work, $30 \%$ related to commuter, and $9 \%$ was associated with leisure PA. The proportions of leisure PA in a recent study [20] and that in our study were similar. Both studies reported a lower proportion of leisure PA among women. However, the higher proportion of leisure PA in another study is difficult to interpret. Still, it could be due to a time effect as the previous study was conducted more than ten years ago. Overall, the higher proportion of PA of the present study compared to previous studies conducted in Bangladesh $[18,19,40]$ could be partly due to the characteristics of the study population. 
Previous studies reported that people with disease conditions are more aware of their risk factors and cautious about their prevention than the general population $[27,28]$.

The current study's prevalence of PA levels was similar to that reported in the east and southeast Asian countries ranging between 15.7-23.9, and sub-Saharan Africa ranging between 15.1-20.5 [41]. A wide variation in PA levels across different parts of the world and within the same country was previously reported $[24,40,42,43]$. In the current study, women, older people, and people with higher socioeconomic status were more likely to be physically inactive. These findings are consistent with previous studies in Bangladesh [18-20,41] and many low- and middle-income countries [24,25,40,42-45]. Irrespective of sex and age, the minimal contribution to the total PA was recreational activity, and the significant contribution was work-related physical activities. The results are also consistent with lowmiddle-income countries [20,24,25,42,45]. Previous studies [18-20,22,41,46] reported that homemakers were associated with a low level of PA, which we also found in our current study.

In contrast to previous studies [18-20,41,47] that reported association of higher education with a low level of PA, the current research found higher education was associated with a higher level of PA, which is consistent with some other studies [22,46]. Association of higher education with a higher PA level could be attributed to increased awareness of health benefit due to PA. Previous studies reported that people were more likely to aware of risk factors and health benefits when they had any health problems $[27,28]$ and acted upon preventing the condition [29]. People with a low level of education were associated with a higher proportion of vigorous-intensity activity but a lower proportion of moderateintensity PA. A higher proportion of moderate-intensity PA level among educated people might indicate that educated people were aware of overall PA. However, possibly due to the nature of their occupations, their participation in vigorous-intensity activity was low. In the current study, farmers were more likely to participate in vigorous-intensity activity than housemakers, employees, or businesspersons, which is the nature of the occupation. Although the results were not significant, employees and businesspersons were more likely to participate in recreational activities. However, recreational activities reported to be minimally contributed to the total PA in Bangladesh and other low-medium-income countries $[20,24,25,42,45]$.

To achieve the most benefit, especially in poor resource settings, there is a need to identify factors associated with different PA levels and types. Most of the previous studies conducted in Bangladesh reported higher education associated with a low level of PA. However, the current research suggests that not higher education but some occupations such as employees and businesspersons were associated with a significantly lower level of PA, especially vigorous-intensity activity. Our study provides further insight into the factors related to PA among people with hypertension in a rural area in Bangladesh. Managing hypertension by changing lifestyle could be the best impactful practice to supplement one of the significant barriers in the health system: the shortage of qualified doctors, especially in rural areas $[48,49]$.

The study has several strengths; for example, data were collected through face-to-face interviews that eliminate possible reporting bias. The study consists of $50 \%$ of women that present the current PA level equally by both genders. However, the research is not free from limitations, such as data being collected from a single rural location, which restricts generalization at the national level. However, the rural residents and the health structure are very comparable in Bangladesh [50].

\section{Conclusions}

Most of the participants met the WHO recommended PA level, and this is predominantly moderate-intensity activity. The PA related to recreation was very minimal. Women, older people, people with no education, and employees were associated with a low overall PA level. Routine PA should be encouraged and organized to increase vigorous-intensity activity and recreational activities to manage high blood pressure. 
Funding: The School of Health Science of Swinburne University Technology provided funds for data collection for this research project. The funders had no role in data collection, analysis, or writing manuscripts.

Institutional Review Board Statement: The study was conducted according to the guidelines of the Declaration of Helsinki, and the research protocol was approved by the Human Research Ethics Committee of the Swinburne University of Technology (Review reference: 20202723-5020) on 26 November 2020.

Informed Consent Statement: Written or verbal consent was obtained from all participants before inclusion. Participants were informed of their rights to withdraw from the study at any stage or to restrict their data from the analysis. Consent was also obtained to publish peer-reviewed manuscripts without disclosing their identity.

Data Availability Statement: The data presented in this study are available on reasonable request from the corresponding author. The data are not publicly available due to the study is ongoing for intervention.

Acknowledgments: I would like to thank Shenae Callija and Kerry de Vent for their critically review the manuscript and language editing. We acknowledge the contribution of Gavin Lambert and Elisabeth Lambert for their review of the ethics application. Rafiqul Islam, Helal Biswas, Sajibul Islam, Mofiz Biswas, and Abidul Islam for their hard work in contacting participants and door-todoor data collection. Finally, we would like to express our gratitude to the study participants for their voluntary participation.

Conflicts of Interest: The author declares that there are no competing interest.

\section{References}

1. Lee, I.M.; Shiroma, E.J.; Lobelo, F.; Puska, P.; Blair, S.N.; Katzmarzyk, P.T.; for the Lancet Physical Activity Series Working Group. Effect of physical inactivity on major non-communicable diseases worldwide: An analysis of burden of disease and life expectancy. Lancet 2012, 380, 219-229. [CrossRef]

2. Warburton, D.E.R.; Bredin, S.S.D. Health benefits of physical activity: A systematic review of current systematic reviews. Curr. Opin. Cardiol. 2017, 32, 541-556. [CrossRef] [PubMed]

3. WHO: Physical Activity Fact Sheet 2016. Available online: https://www.who.int/news-room/fact-sheets/detail/physicalactivity (accessed on 30 June 2021).

4. Sallis, J.F.; Bull, F.; Guthold, R.; Heath, G.W.; Inoue, S.; Kelly, P.; Oyeyemi, A.L.; Perez, L.G.; Richards, J.; Hallal, P.C.; et al. Progress in physical activity over the Olympic quadrennium. Lancet 2016, 388, 1325-1336. [CrossRef]

5. Powell, K.E.; Paluch, A.E.; Blair, S.N. Physical activity for health: What kind? How much? How intense? On top of what? Annu. Rev. Public Health 2011, 32, 349-365. [CrossRef]

6. $\quad$ Manson, J.E.; Greenland, P.; LaCroix, A.Z.; Stefanick, M.L.; Mouton, C.P.; Oberman, A.; Perri, M.G.; Sheps, D.S.; Pettinger, M.B.; Siscovick, D.S. Walking compared with vigorous exercise for the prevention of cardiovascular events in women. N. Engl. J. Med. 2002, 347, 716-725. [CrossRef] [PubMed]

7. Samitz, G.; Egger, M.; Zwahlen, M. Domains of physical activity and all-cause mortality: Systematic review and dose-response meta-analysis of cohort studies. Int. J. Epidemiol. 2011, 40, 1382-1400. [CrossRef]

8. Global Action Plan for the Prevention and Control of NCDs 2013-2020. Available online: https://www.who.int/publications/i/ item/9789241506236 (accessed on 9 July 2021).

9. Lear, S.A.; Hu, W.; Rangarajan, S.; Gasevic, D.; Leong, D.; Iqbal, R.; Casanova, A.; Swaminathan, S.; Anjana, R.M.; Kumar, R.; et al. The effect of physical activity on mortality and cardiovascular disease in 130,000 people from 17 high-income, middle-income, and low-income countries: The PURE study. Lancet 2017, 390, 2643-2654. [CrossRef]

10. Tareque, M.I.; Hoque, N.; Islam, T.M.; Kawahara, K.; Sugawa, M. Relationships between the Active Aging Index and DisabilityFree Life Expectancy: A Case Study in the Rajshahi District of Bangladesh. Can. J. Aging 2013, 32, 417-432. [CrossRef] [PubMed]

11. Hossain, N. Post-conflict ruptures and the space for women's empowerment in Bangladesh. Women's Stud. Int. Forum 2019, 68, 104-112. [CrossRef]

12. Khan, M.A.H.; Cruz, V.O.; Azad, A.K. Bangladesh's digital health journey: Reflections on a decade of quiet revo-lution. WHO South East Asia J. Public Health 2019, 8, 71-76.

13. Siegel, K.R.; Patel, S.A.; Ali, M.K. Non-communicable diseases in South Asia: Contemporary perspectives. Br. Med. Bull. 2014, 111,31-44. [CrossRef] [PubMed]

14. Ghaffar, A.; Reddy, K.S.; Singhi, M. Burden of non-communicable diseases in South Asia. BMJ 2004, 328, 807-810. [CrossRef]

15. Narain, J.P.; Garg, R.; Fric, A. Non-communicable diseases in the South-East Asia region: Burden, strategies and opportunities. Natl. Med. J. India 2011, 24, 280-287. [PubMed] 
16. Murray, C.J.; Barber, R.M.; Foreman, K.J.; Abbasoglu Ozgoren, A.; Abd-Allah, F.; Abera, S.F.; Aboyans, V.; Abraham, J.P.; Abubakar, I.; Abu-Raddad, L.J.; et al. Global, regional, and national disability-adjusted life years (DALYs) for 306 diseases and injuries and healthy life expectancy (HALE) for 188 countries, 1990-2013: Quantifying the epidemiological transition. Lancet 2015, 386, 2145-2191. [CrossRef]

17. Vos, T.; Flaxman, A.D.; Naghavi, M.; Lozano, R.; Michaud, C.; Ezzati, M.; Shibuya, K.; Salomon, J.A.; Abdalla, S.; Aboyans, V.; et al. Years lived with disability (YLDs) for 1160 sequelae of 289 diseases and injuries 1990-2010: A systematic analysis for the Global Burden of Disease Study 2010. Lancet 2012, 380, 2163-2196. [CrossRef]

18. Moniruzzaman, M.; Mostafa Zaman, M.; Islalm, M.S.; Ahasan, H.A.; Kabir, H.; Yasmin, R. Physical activity levels in Bangladeshi adults: Results from STEPS survey 2010. Public Health 2016, 137, 131-138. [CrossRef]

19. Zaman, M.M.; Rahman, M.M.; Rahman, M.R.; Bhuiyan, M.R.; Karim, M.N.; Chowdhury, M.A. Prevalence of risk factors for non-communicable diseases in Bangladesh: Results from STEPS survey 2010. Indian J. Public Health 2016, 60, 17-25. [CrossRef]

20. Moniruzzaman, M.; Ahmed, M.S.; Zaman, M.M. Physical activity levels and associated socio-demographic factors in Bangladeshi adults: A cross-sectional study. BMC Public Health 2017, 17, 59. [CrossRef]

21. Pedisic, Z.; Shrestha, N.; Loprinzi, P.D.; Mehata, S.; Mishra, S.R. Prevalence, patterns, and correlates of physical activity in Nepal: Findings from a nationally representative study using the Global Physical Activity Ques-tionnaire (GPAQ). BMC Public Health 2019, 19, 864. [CrossRef]

22. Guwatudde, D.; Kirunda, B.E.; Wesonga, R.; Mutungi, G.; Kajjura, R.; Kasule, H.; Muwonge, J.; Bahendeka, S.K. Physical Activity Levels Among Adults in Uganda: Findings from a Countrywide Cross-Sectional Survey. J. Phys. Act. Health 2016, 13, 938-945. [CrossRef]

23. Padrao, P.; Damasceno, A.; Silva-Matos, C.; Prista, A.; Lunet, N. Physical activity patterns in Mozambique: Urban/rural differences during epidemiological transition. Prev. Med. 2012, 55, 444-449. [CrossRef]

24. Bauman, A.; Bull, F.; Chey, T.; Craig, C.L.; Ainsworth, B.E.; Sallis, J.F.; Bowles, H.R.; Hagstromer, M.; Sjostrom, M.; Pratt, M.; et al. The International Prevalence Study on Physical Activity: Results from 20 countries. Int. J. Behav. Nutr. Phys. Act. $2009,6,21$. [CrossRef] [PubMed]

25. Trinh, O.T.; Nguyen, N.D.; Dibley, M.J.; Phongsavan, P.; Bauman, A.E. The prevalence and correlates of physical inactivity among adults in Ho Chi Minh City. BMC Public Health 2008, 8, 204. [CrossRef]

26. Zaman, M.M.; Bhuiyan, M.R.; Karim, M.N.; MoniruzZaman Rahman, M.M.; Akanda, A.W.; Fernando, T. Clustering of noncommunicable diseases risk factors in Bangladeshi adults: An analysis of STEPS survey 2013. BMC Public Health 2015, 15, 659 .

27. Islam, F.M.; Chakrabarti, R.; Dirani, M.; Islam, M.T.; Ormsby, G.; Wahab, M.; Critchley, C.; Finger, R.P. Knowledge, Attitudes and Practice of Diabetes in Rural Bangladesh: The Bangladesh Population Based Diabetes and Eye Study (BPDES). PLoS ONE 2014, 9 , e110368. [CrossRef]

28. Islam, F.M.; Chakrabarti, R.; Islam, S.Z.; Finger, R.P.; Critchley, C. Factors Associated with Awareness, Attitudes and Practices Regarding Common Eye Diseases in the General Population in a Rural District in Bangladesh: The Bangladesh Population-based Diabetes and Eye Study (BPDES). PLoS ONE 2015, 10, e0133043. [CrossRef] [PubMed]

29. Islam, F.M.A.; Kawasaki, R.; Finger, R.P. Factors associated with participation in a diabetic retinopathy screening program in a rural district in Bangladesh. Diabetes Res. Clin. Pract. 2018, 144, 111-117. [CrossRef]

30. Cardiovascular Disease: A Global Brief on Hypertension. WHO/DCO/WHD/2013.2. Available online: https://apps.who.int/ iris/bitstream/handle/10665/79059/WHO_DCO_WHD_2013.2_eng.pdf;jsessionid=1B55AAB65171500021AA378EB0D71E99? sequence $=1$ (accessed on 9 July 2021).

31. Mills, K.T.; Bundy, J.D.; Kelly, T.N.; Reed, J.E.; Kearney, P.M.; Reynolds, K.; Chen, J.; He, J. Global Disparities of Hypertension Prevalence and Control: A Systematic Analysis of Population-Based Studies from 90 Countries. Circulation 2016, 134, 441-450. [CrossRef]

32. Islam, F.M.A.; Lambert, E.A.; Islam, S.M.S.; Islam, M.A.; Maddison, R.; Thompson, B.; Lambert, G.W. Factors associated with uncontrolled blood pressure and the adherence to antihypertensive medication in a rural area in Bangladesh: Baseline data from a cluster Randomized Control Trial. BMC Public Health 2021. submitted.

33. Bangladesh Bureau of Statistics. Population and Housing Census. 2011. Available online: http://203.112.218.65: 8008/WebTestApplication/userfiles/Image/National\%20Reports/Population\%20\%20Housing\%20Census\%202011.pdf (accessed on 30 June 2021).

34. Islam, F.M.A.; Lambert, E.A.; Islam, S.M.S.; Islam, M.A.; Biswas, D.; McDonald, R.; Maddison, R.; Thompson, B.; Lambert, G.W. Lowering blood pressure by changing lifestyle through a motivational education program: A cluster randomized controlled trial study protocol. Trials 2021, 22, 438. [CrossRef]

35. Islam, F.M.A.; Chakrabarti, R.; Islam, M.T.; Wahab, M.; Lamoureux, E.; Finger, R.P.; Shaw, J.E. Prediabetes, diagnosed and undiagnosed diabetes, their risk factors and association with knowledge of diabetes in rural Bangladesh: The Bangladesh Population-based Diabetes and Eye Study. J. Diabetes 2016, 8, 260-268. [CrossRef]

36. Islam, F.M.; Bhuiyan, A.; Chakrabarti, R.; Rahman, M.A.; Kanagasingam, Y.; Hiller, J.E. Undiagnosed hypertension in a rural district in Bangladesh: The Bangladesh Population-based Diabetes and Eye Study (BPDES). J. Hum. Hypertens. 2016, 30, $252-259$. [CrossRef] 
37. Whelton, P.K.; Carey, R.M.; Aronow, W.S.; Casey, D.E., Jr.; Collins, K.J.; Dennison Himmelfarb, C.; DePalma, S.M.; Gid-ding, S.; Jamerson, K.A.; Jones, D.W.; et al. 2017 ACC/AHA/AAPA/ABC/ACPM/AGS/APhA/ASH/ASPC/NMA/PCNA Guideline for the Prevention, Detection, Evaluation, and Management of High Blood Pressure in Adults: A Report of the American College of Cardiology/American Heart Association Task Force on Clinical Practice Guidelines. J. Am. Coll. Cardiol. 2018, 71, e127-e248. [PubMed]

38. Department of Chronic Diseases and Health Promotion, WHO. GPAQ: Global Physical Activity Questionnaire (Version 2.0). Available online: https:/ / www.who.int/ncds/surveillance/steps/GPAQ_EN.pdf (accessed on 9 July 2021).

39. Cheng, Y.H.; Chi, I.; Boey, K.W.; Ko, L.S.; Chou, K.L. Self-rated economic condition and the health of elderly persons in Hong Kong. Soc. Sci. Med. 2002, 55, 1415-1424. [CrossRef]

40. Macniven, R.; Bauman, A.; Abouzeid, M. A review of population-based prevalence studies of physical activity in adults in the Asia-Pacific region. BMC Public Health 2012, 12, 41. [CrossRef]

41. Razzaque, A.; Nahar, L.; Abu Haider Mohammad Golam, M.; Karar Zunaid, A.; Mohammad Shafiqul, I.; Yunus, M. Sociodemographic differentials of selected noncommunicable diseases risk factors among adults in Matlab, Bangladesh: Findings from a WHO STEPS survey. Asia Pac. J. Public Health Asia Pac. Acad. Consort. Public Health 2011, 23, 183-191. [CrossRef]

42. Ng, N.; Hakimi, M.; Van Minh, H.; Juvekar, S.; Razzaque, A.; Ashraf, A.; Masud Ahmed, S.; Kanungsukkasem, U.; Soonthornthada, K.; Huu Bich, T. Prevalence of physical inactivity in nine rural INDEPTH Health and Demographic Surveillance Systems in five Asian countries. Glob. Health Action 2009, 2, 1985. [CrossRef] [PubMed]

43. Guthold, R.; Ono, T.; Strong, K.L.; Chatterji, S.; Morabia, A. Worldwide variability in physical inactivity a 51-country survey. Am. J. Prev. Med. 2008, 34, 486-494. [CrossRef]

44. Dumith, S.C.; Hallal, P.C.; Reis, R.S.; Kohl, H.W., 3rd. Worldwide prevalence of physical inactivity and its association with human development index in 76 countries. Prev. Med. 2011, 53, 24-28. [CrossRef]

45. Bennett, D.A.; Du, H.; Clarke, R.; Guo, Y.; Yang, L.; Bian, Z.; Chen, Y.; Millwood, I.; Yu, C.; He, P.; et al. Association of Physical Activity With Risk of Major Cardiovascular Diseases in Chinese Men and Women. JAMA Cardiol. 2017, 2, 1349-1358. [CrossRef]

46. John, B.; Todd, J.; Mboya, I.; Mosha, M.; Urassa, M.; Mtuy, T. Physical activity and associated factors from a cross-sectional survey among adults in northern Tanzania. BMC Public Health 2017, 17, 588. [CrossRef] [PubMed]

47. Marques, A.; Martins, J.; Sarmento, H.; Ramos, M.; Diniz, J.; Costa, F.C. Socio-demographic correlates of leisure time physical activity among Portuguese adults. Cademos de Saude Publica 2015, 31, 1061-1070. [CrossRef] [PubMed]

48. Ahmed, S.M.; Hossain, M.A.; Rajachowdhury, A.M.; Bhuiya, A.U. The health workforce crisis in Bangladesh: Shortage, inappropriate skill-mix and inequitable distribution. Hum. Resour. Health 2011, 9, 3. [CrossRef] [PubMed]

49. GHWA. Global Health Workforce Alliance 2016. Available online: https://www.who.int/workforcealliance/en/ (accessed on 30 June 2021).

50. Bangladesh: Standard DHS. 2011. Available online: https:/ / dhsprogram.com/pubs/pdf/PR15/PR15.pdf (accessed on 30 June 2021). 